\title{
Efficacy and safety of lenvatinib versus sorafenib for unresectable hepatocellular carcinoma: A meta-analysis
}

wei fan sui ( $\sim$ Sui-suiweifan@163.com )

Zhenjiang First People's Hospital

jian yun li

Zhenjiang First People's Hospital

jian hua fu

Zhenjiang First People's Hospital

\section{Research}

Keywords: hepatocellular carcinoma, lenvatinib, sorafenib, meta-analysis, systemic therapy

Posted Date: September 8th, 2020

DOI: https://doi.org/10.21203/rs.3.rs-68877/v1

License: (9) (1) This work is licensed under a Creative Commons Attribution 4.0 International License. Read Full License 


\section{Abstract \\ Background}

Although sorafenib was recommended as a first-line systemic therapy to prolong overall survival time in unresectable hepatocellular carcinoma (HCC), two randomized phase 3 noninferiority trials demonstrated that lenvatinib was noninferior to sorafenib in unresectable HCC.

\section{Methods}

This study included three trials containing 1462 patients identified by a database search using standard terms. We conducted the data analysis in Review Manager version 5.3 software.

\section{Results}

The outcomes showed that there were nonsignificant differences in OS of $6,12,18,30$ and 36 months, PFS of $18,24,30$ and 36 months and AEs (grade $<3$ ) between the lenvatinib group and the sorafenib group, and there were significant differences in OS of 24 months $(p=0.01)$, PFS of $6(p<0.00001)$ and $12(p<0.00001)$ months, ORR $(p<0.00001)$ and DCR $(p<0.00001)$ between the lenvatinib group and the sorafenib group.

\section{Conclusions}

Lenvatinib was not superior to sorafenib in terms of OS and AEs, and lenvatinib was superior to sorafenib in terms of secondary endpoints, including PFS, ORR and DCR, in unresectable HCC.

\section{Background}

Hepatocellular carcinoma (HCC), as the most common type of liver cancer, is the sixth most common cancer worldwide[1]. Most HCC patients have accompanying chronic liver disease and have lost the chance for surgical resection. Originally, sorafenib, as an inhibitor of multiple protein kinases, was recommended as a first-line systemic therapy to prolong the overall survival time in unresectable $\mathrm{HCC}[2,3]$. Moreover, all phase 3 trials, including of sunitinib, brivanib and linifanib, had demonstrated that these oral targeted drugs were inferior to sorafenib in the first-line treatment of unresectable $\mathrm{HCC}[4-6]$. However, low response rate and toxicities limited the clinical application of sorafenib[7].

Lenvatinib is an antiangiogenic oral target drug acting as a multikinase inhibitor of VEGFR1-3, FGFR1-4, PDGFR-a, RET, and $\mathrm{KIT}$ [8-10]. Lenvatinib is approved for antiangiogenic therapy in the treatment of radioiodine-refractory differentiated thyroid cancer and advanced renal cell carcinoma[11, 12]. Lenvatinib was demonstrated to be noninferior to sorafenib in overall survival in unresectable HCC in a phase 3, multicenter, randomized, open-label, noninferiority trial[13]. Furthermore, subsequent systemic therapy of lenvatinib also showed clinical efficacy and acceptable safety in unresectable HCC[14].

Given the observations from previous studies and the lack of data to assess the efficacy and safety of lenvatinib versus sorafenib for unresectable HCC, we conducted a meta-analysis to provide clinically useful information about the efficacy and safety of lenvatinib versus sorafenib for unresectable HCC.

\section{Methods}

\section{Systematic literature review}

We performed a systematic search of the PubMed and Cochrane Central Register of Controlled Trials databases from their establishment to 1 March 2020. The search used the following keywords: hepatocellular carcinoma, lenvatinib and sorafenib. A comparison between lenvatinib and sorafenib in unresectable HCC must have occurred in the included studies.

Page 2/11 


\section{Data extraction and quality assessment}

The following characteristics of the included studies were extracted by two reviewers: author, year of publication, study design, number of patients in the experimental and control groups, follow-up period and outcomes. Additionally, the qualities of the included studies were assessed by the Cochrane Collaboration risk of bias tool.

\section{Statistical analysis}

Statistical analysis was performed using Review Manager version 5.3 software. First, we compared outcomes, including overall survival (OS) and progression-free survival (PFS) after 6, 12, 18, 24, 30, and 36 months, objective response rate (ORR), disease control rate $(\mathrm{DCR})$ and adverse effects $(\mathrm{AEs}$, grade $<3)$. The $p$ value of the $Z$ test was used to evaluate the overall effect size, with a $p<0.05$ signifying a significant difference between the observed and control groups. Heterogeneity was quantitatively assessed by $I^{2}$ statistics, with an $I^{2} \geq 50 \%$ signifying that heterogeneity existed. Second, to explore the source of heterogeneity, subgroup and sensitivity analyses were conducted. Finally, funnel plots were used to evaluate publication bias. A symmetrical funnel plot signified that no publication bias existed.

\section{Results}

\section{Systematic literature review}

A total of 169 records were identified through the database search. A total of 152 studies were excluded after eligibility screening, and the full texts of 17 potentially eligible studies were assessed. Consequently, 3 trials[13-15] were included in the quantitative analysis (Fig. 1).

\section{Data extraction and quality assessment}

Table 1 shows the characteristics of the included studies. Study design, dosage of target therapy, and follow-up were the same in all three included studies. Nation was the same in two studies[13, 14]. Outcomes were the same in two studies[13, 15]. The study design of the three studies was a phase 3 , multicenter, randomized, open-label, noninferiority trial. The dosages of lenvatinib and sorafenib were the same in all three studies.

The results of the quality assessment in the three studies are shown in Fig. 2. Figure 2 summarizes the assessment of random sequence generation (selection bias), allocation concealment (selection bias), blinding of participants and personnel (performance bias), blinding of outcome assessment (detection bias), incomplete outcome data (attrition bias), selective reporting (reporting bias), and other sources of bias. The investigations identified as low risk, unclear risk or high risk are represented as green, yellow and red colors, respectively. In this meta-analysis, the three included studies were proved to be of high quality.

\section{Statistical analysis}

The forest plot indicated that there were nonsignificant differences in the OS of 6, 12, 18, 30 and 36 months between the lenvatinib group and the sorafenib group (Fig. 3A-C,E,F). The forest plot also indicated that there was a significant difference in an OS of 24 months $(\mathrm{OR}, 95 \% \mathrm{Cl}, 1.38[1.08,1.77], \mathrm{p}=0.01)$ between the lenvatinib group and the sorafenib group (Fig. 4D). No heterogeneity was found $\left(I^{2}=0\right)$.

The forest plot indicated that there were significant differences in a PFS of $6(\mathrm{OR}, 95 \% \mathrm{Cl}, 2.11[1.65,2.70], \mathrm{p}<0.00001)$ and 12 months $(\mathrm{OR}, 95 \% \mathrm{Cl}, 2.32[1.66,3.32], \mathrm{p}<0.00001)$ between the lenvatinib group and the sorafenib group (Fig. 4A,B). The forest plot also indicated that there were nonsignificant differences in a PFS of 18, 24, 30 and 36 months (Fig. 4C-F). No heterogeneity was found $\left({ }^{2}<50 \%\right)$.

The forest plot indicated that there were significant differences in the ORR (OR, 95\% Cl, 5.01[3.70, 6.77], $\mathrm{p}<0.00001)$ and DCR (OR, $95 \% \mathrm{Cl}, 2.04[1.58,2.62], \mathrm{p}<0.00001)$ between the lenvatinib group and the sorafenib group (Fig. 5). No heterogeneity was found $\left(I^{2}=0\right)$. 
The forest plot indicated that there was a nonsignificant difference in AEs (grade < 3) between the lenvatinib group and the sorafenib group (Fig. 6). Heterogeneity was found $\left(I^{2}=72 \%\right)$. Due to the limited number of included studies, the source of heterogeneity was not explored.

The funnel plot was symmetrical, indicating that no publication bias existed (Fig. 7).

\section{Discussion}

This meta-analysis provided data from three randomized phase 3 noninferiority trials to evaluate the efficacy and safety of lenvatinib versus sorafenib for unresectable HCC. The results indicated that the objective responses, including ORR, DCR and PFS, were better with lenvatinib than with sorafenib, consistent with previous studies. However, the results of OS and AEs indicated that the efficacy and safety of lenvatinib were not markedly better than those of sorafenib.

As an oral multikinase inhibitor, lenvatinib selectively acts on more kinase activities and proangiogenic and oncogenic pathways than sorafenib, particularly fibroblast growth factor (FGF) signaling. Recent research demonstrated that FGF signaling might be a cause of acquired resistance to sorafenib posttreatment[16, 17]. Hence, lenvatinib was considered to have theoretically better performance in improving OS and tumor responses, including ORR and DCR[8-10]. However, in practice, lenvatinib was not superior to sorafenib in terms of OS.

OS is regarded as the primary endpoint to evaluate the efficacy of all types of anticancer therapies according to mRECIST[18]. Our meta-analysis emphasized that lenvatinib was not superior to sorafenib in improving the OS in unresectable HCC, consistent with previous studies[13-15]. Based on reviewing the patients in the selected trials, we may generalize the following reasons for these findings. First, multimodality therapies may be efficacious and were performed after systemic therapies such as lenvatinib or sorafenib treatment[19], which could make OS as an endpoint alone unable to completely capture the full extent of anticancer efficacy. Second, the heterogeneity of the baseline characteristics of unresectable HCC patients, such as serum AFP, BCLC stage[20] and ECOG PS[21], could dilute the treatment benefit of the observed OS. Third, the relatively small number of included studies in this meta-analysis might affect the treatment outcomes.

PFS, ORR and DCR were treated as the secondary endpoints according to mRECIST. Our meta-analysis highlighted that lenvatinib improved PFS, ORR and DCR compared with sorafenib, similar to previous research[13-15].

The result regarding AEs in this meta-analysis indicated that the safety of lenvatinib was not superior to that of sorafenib. Our results were consistent with previous research[11,22]. The most common AEs of lenvatinib in the selected studies were hypertension, diarrhea, decreased appetite and weight reduction. The most common AEs of sorafenib were palmar-plantar erythrodysesthesia syndrome (PPES), diarrhea, hypertension and decreased appetite. These AEs were class effects of VEGFtargeted therapies and were manageable. The AEs were associated with dose, and they were managed by dose modifications.

$\mathrm{HCC}$ is distinct from other cancer types. HCC patients usually experience hepatic impairment to various degrees, and increased systematic therapies can aggravate hepatic impairment[23]. Furthermore, the metabolism of lenvatinib occurs mainly in the liver[24], and lenvatinib pharmacokinetics have been shown to be affected by bodyweight[25]. Hence, the initial and subsequently modified dosages of lenvatinib were of significance to preserve the balance between efficacy maintenance and toxicity reduction. Based on previous studies[13,15,], currently, doses of $8 \mathrm{mg}$ for bodyweight less than $60 \mathrm{~kg}$ and $12 \mathrm{mg}$ for bodyweight greater than or equal to $60 \mathrm{~kg}$ is optimal for lenvatinib treatment in unresectable HCC.

We should acknowledge the limitations in our meta-analysis. First, there were not enough high-quality prospective studies included. Second, due to the number of selected studies, the source of heterogeneity was not found. Third, although no significant publication bias existed, the potential publication bias could not be neglected.

\section{Conclusions}

This meta-analysis showed that lenvatinib was not superior to sorafenib in terms of OS and AEs and that lenvatinib was superior to sorafenib in terms of the secondary endpoints, including PFS, ORR and DCR, in unresectable HCC. 


\section{Abbreviations}

HCC: hepatocellular carcinoma; OS:overall survival; PFS:progression-free surviva; ORR:objective response rate; DCR:disease control rate; AEs:adverse effects; FGF:fibroblast growth factor; PPES:palmar-plantar erythrodysesthesia syndrome

\section{Declarations}

\section{Ethics approval and consent to participate:}

Not applicable

Consent for publication:

Not applicable

Availability of data and materials:

Not applicable

Competing interests:

None

\section{Funding:}

None

\section{Authors' contributions -}

WFS wrote the first draft of the manuscript and contributed to the data collection and analysis. JYL and JHF contributed to the study design. Acknowledgements: None

\section{References}

1. Torre LA, Bray F, Siegel RL, et al. Global cancer statistics, 2012[J]. Cancer J Clin. 2015;65(2):87-108.

2. Llovet JM, Ricci S, Mazzaferro V, et al. Sorafenib in advanced hepatocellular carcinoma[J]. New England journal of medicine. 2008;359(4):378-90.

3. Cheng AL, Kang YK, Chen Z, et al. Efficacy and safety of sorafenib in patients in the Asia-Pacific region with advanced hepatocellular carcinoma: a phase III randomised, double-blind, placebo-controlled trial[J]. The lancet oncology. 2009;10(1):25-34.

4. Cheng AL, Kang YK, Lin DY, et al. Sunitinib versus sorafenib in advanced hepatocellular cancer: results of a randomized phase III trial[J]. Journal of clinical oncology. 2013;31(32):4067-75.

5. Johnson PJ, Qin S, Park JW, et al. Brivanib versus sorafenib as first-line therapy in patients with unresectable, advanced hepatocellular carcinoma: results from the randomized phase III BRISK-FL study[J]. J Clin Oncol. 2013;31(28):3517-24.

6. Cainap C, Qin S, Huang WT, et al. Linifanib versus Sorafenib in patients with advanced hepatocellular carcinoma: results of a randomized phase III trial[J]. J Clin Oncol. 2015;33(2):172-9.

7. Yau T, Chan P, Ng K, et al. Efficacy and tolerability of single agent sorafenib in poor risk advanced hepatocellular carcinoma patients[J]. J Clin Oncol. 2008;26(15_suppl):15513-3.

8. Matsui J, Funahashi Y, Uenaka T, et al. Multi-kinase inhibitor E7080 suppresses lymph node and lung metastases of human mammary breast tumor MDA-MB-231 via inhibition of vascular endothelial growth factor-receptor (VEGF-R) 2 and VEGF-R3 
kinase[J]. Clin Cancer Res. 2008;14(17):5459-65.

9. Tohyama O, Matsui J, Kodama K, et al. Antitumor activity of lenvatinib (e7080): an angiogenesis inhibitor that targets multiple receptor tyrosine kinases in preclinical human thyroid cancer models[J]. Journal of thyroid research. 2014;2014:638747.

10. Yamamoto Y, Matsui J, Matsushima T, et al. Lenvatinib, an angiogenesis inhibitor targeting VEGFR/FGFR, shows broad antitumor activity in human tumor xenograft models associated with microvessel density and pericyte coverage[J]. Vascular cell. 2014;6(1):18.

11. Schlumberger M, Tahara M, Wirth LJ, et al. Lenvatinib versus placebo in radioiodine-refractory thyroid cancer[J]. N Engl J Med. 2015;372(7):621-30.

12. Motzer RJ, Hutson TE, Glen H, et al. Lenvatinib, everolimus, and the combination in patients with metastatic renal cell carcinoma: a randomised, phase 2, open-label, multicentre trial[J]. The lancet oncology. 2015;16(15):1473-82.

13. Kudo M, Finn RS, Qin S, et al. Lenvatinib versus sorafenib in first-line treatment of patients with unresectable hepatocellular carcinoma: a randomised phase 3 non-inferiority trial[J]. The Lancet. 2018;391(10126):1163-73.

14. Alsina A, Kudo M, Vogel A, et al. Effects of Subsequent Systemic Anticancer Medication Following First-Line Lenvatinib: A Post Hoc Responder Analysis from the Phase 3 REFLECT Study in Unresectable Hepatocellular Carcinoma[J]. Liver Cancer. 2020;9(1):93-104.

15. Yamashita T, Kudo M, Ikeda K, et al. REFLECT-a phase 3 trial comparing efficacy and safety of lenvatinib to sorafenib for the treatment of unresectable hepatocellular carcinoma: an analysis of Japanese subset[J]. Journal of gastroenterology. 2020;55(1):113-22.

16. Tovar V, Cornella H, Moeini A, et al. Tumour initiating cells and IGF/FGF signalling contribute to sorafenib resistance in hepatocellular carcinoma[J]. Gut. 2017;66(3):530-40.

17. Gao L, Wang X, Tang Y, et al. FGF19/FGFR4 signaling contributes to the resistance of hepatocellular carcinoma to sorafenib[J]. Journal of Experimental Clinical Cancer Research. 2017;36(1):8.

18. Lencioni R, Montal R, Torres F, et al. Objective response by mRECIST as a predictor and potential surrogate end-point of overall survival in advanced HCC[J]. Journal of hepatology. 2017;66(6):1166-72.

19. Terashima T, Yamashita T, Arai K, et al. Feasibility and efficacy of hepatic arterial infusion chemotherapy for advanced hepatocellular carcinoma after sorafenib[J]. Hepatol Res. 2014;44(12):1179-85.

20. Bruix J, Cheng AL, Meinhardt G, et al. Prognostic factors and predictors of sorafenib benefit in patients with hepatocellular carcinoma: Analysis of two phase III studies[J]. Journal of hepatology. 2017;67(5):999-1008.

21. Kudo M, Ikeda M, Takayama T, et al. Safety and efficacy of sorafenib in Japanese patients with hepatocellular carcinoma in clinical practice: a subgroup analysis of GIDEON[J]. Journal of gastroenterology. 2016;51(12):1150-60.

22. Ikeda K, Kudo M, Kawazoe S, et al. Phase 2 study of lenvatinib in patients with advanced hepatocellular carcinoma[J]. Journal of gastroenterology. 2017;52(4):512-9.

23. Shumaker R, Aluri J, Fan J, et al. Influence of hepatic impairment on lenvatinib pharmacokinetics following single-dose oral administration[J]. The Journal of Clinical Pharmacology. 2015;55(3):317-27.

24. Inoue $\mathrm{K}$, Asai $\mathrm{N}$, Mizuo H, et al. Unique metabolic pathway of [14C] lenvatinib after oral administration to male cynomolgus monkey[J]. Drug Metab Dispos. 2012;40(4):662-70.

25. Gupta A, Jarzab B, Capdevila J, et al. Population pharmacokinetic analysis of lenvatinib in healthy subjects and patients with cancer[J]. Br J Clin Pharmacol. 2016;81(6):1124-33.

26. Tamai T, Hayato S, Hojo S, et al. Dose finding of lenvatinib in subjects with advanced hepatocellular carcinoma based on population pharmacokinetic and exposure-response analyses[J]. The Journal of Clinical Pharmacology. 2017;57(9):1138-47.

\section{Tables}

Table 1. The characteristics of the included studies 


\begin{tabular}{|c|c|c|c|c|c|c|c|c|}
\hline \multirow[t]{2}{*}{ Author(year) } & \multirow[t]{2}{*}{ Nation } & \multirow[t]{2}{*}{$\begin{array}{l}\text { Study } \\
\text { design }\end{array}$} & \multicolumn{2}{|c|}{$\begin{array}{l}\text { Number of } \\
\text { patients(M/F) }\end{array}$} & \multirow{2}{*}{\multicolumn{2}{|c|}{$\begin{array}{l}\text { Dosage } \\
\text { len group } \\
\text { sor group }\end{array}$}} & \multirow[t]{2}{*}{$\begin{array}{l}\text { Follow- } \\
\text { up }\end{array}$} & \multirow[t]{2}{*}{ Outcomes } \\
\hline & & & $\begin{array}{l}\text { len grou } \\
\text { group }\end{array}$ & & & & & \\
\hline $\begin{array}{l}\text { Masatoshi } \\
\text { Kudo(2018) }\end{array}$ & Western & \multirow{5}{*}{$\begin{array}{l}\text { randomised } \\
\text { phase } 3 \\
\text { non- } \\
\text { inferiority } \\
\text { trial }\end{array}$} & $405 / 73$ & $401 / 75$ & \multirow{5}{*}{$\begin{array}{l}12 \mathrm{mg} / \text { day } \\
\text { (for } \\
\text { bodyweight } \\
\geq 60 \mathrm{~kg} \text { ) } \\
8 \mathrm{mg} / \text { day } \\
\text { (for } \\
\text { bodyweight } \\
<60 \mathrm{~kg} \text { ) }\end{array}$} & \multirow{5}{*}{$\begin{array}{l}\text { 400mg } \\
\text { twice } \\
\text { daily }\end{array}$} & \multirow{5}{*}{$\begin{array}{l}42 \\
\text { month }\end{array}$} & \multirow{2}{*}{$\begin{array}{l}\text { OS,PFS,TTP,ORR,DCR } \\
\text { AES }\end{array}$} \\
\hline & $\begin{array}{l}\text { Asia- } \\
\text { Pacific }\end{array}$ & & & & & & & \\
\hline $\begin{array}{l}\text { Tatsuya } \\
\text { Yamashita(2020) }\end{array}$ & Japan & & $65 / 16$ & $72 / 15$ & & & & $\begin{array}{l}\text { OS,PFS,TTP,ORR,DCR, } \\
\text { AES }\end{array}$ \\
\hline \multirow{2}{*}{$\begin{array}{l}\text { Angel } \\
\text { Alsina(202) }\end{array}$} & Western & & \multirow[t]{2}{*}{156} & \multirow[t]{2}{*}{184} & & & & \multirow[t]{2}{*}{ OS } \\
\hline & $\begin{array}{l}\text { Asia- } \\
\text { Pacific }\end{array}$ & & & & & & & \\
\hline
\end{tabular}

len: lenvatinib, sor: sorafenib, OS:overall survival, PFS: progression-free survival, TTP: time to progression, ORR: objective response rate, DCR: disease control rate, AEs: adverse events.

\section{Figures}

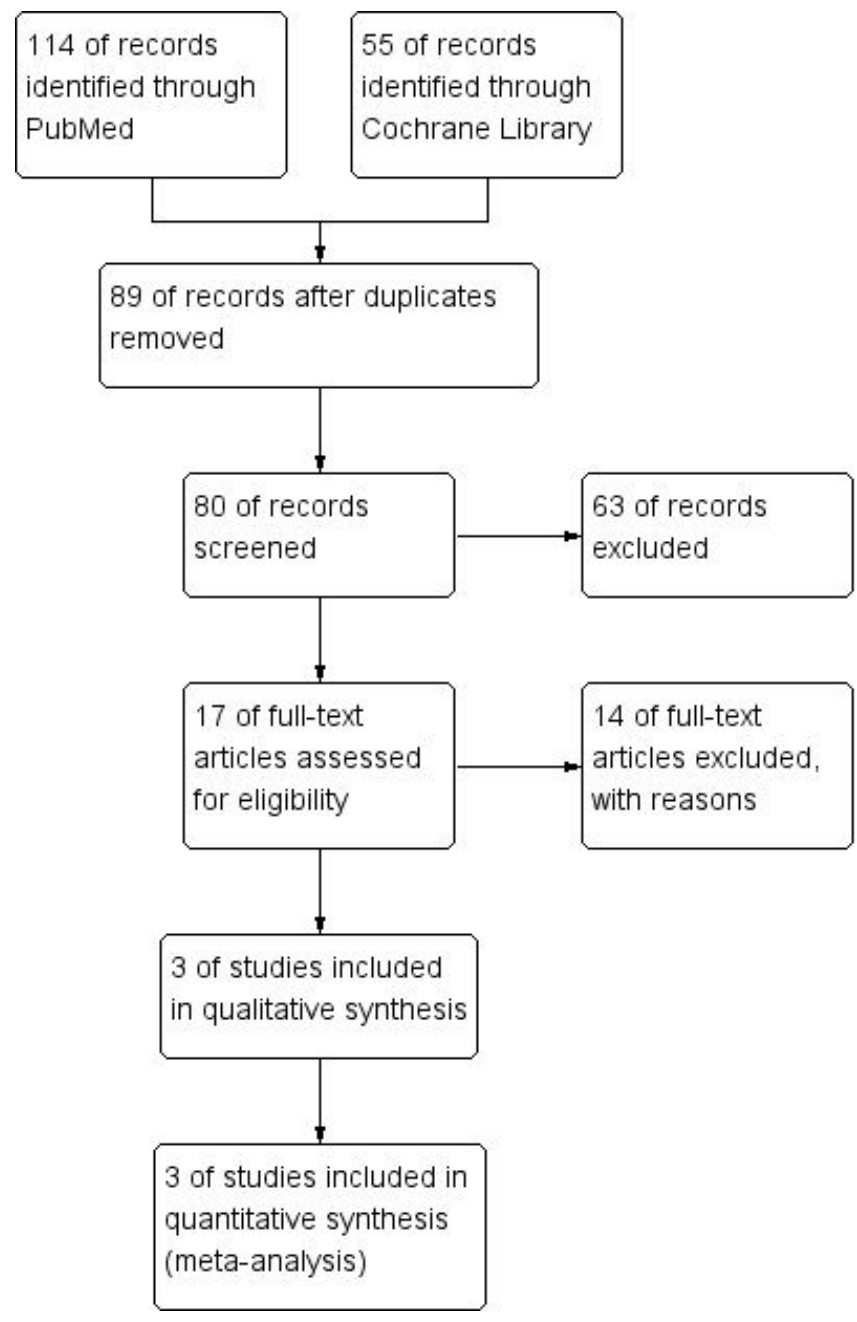

\section{Figure 1}

Flowchart showing the flow of information through the different phases of the systematic review toward a meta-analysis 


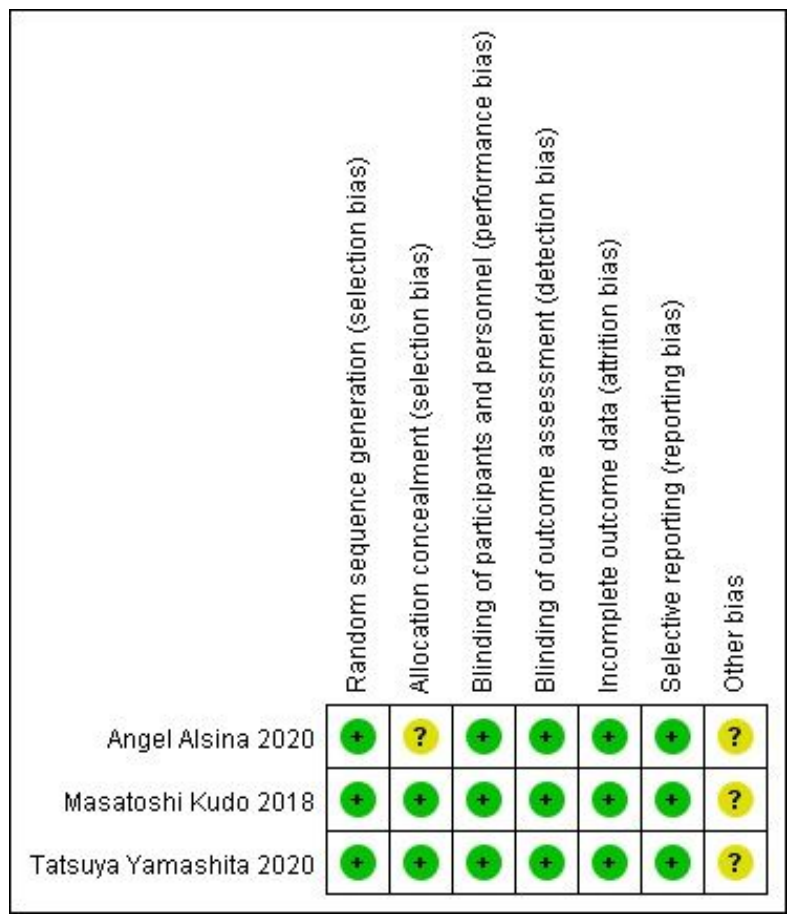

\section{Figure 2}

Risk of bias summary: review of authors' judgments about each risk of bias item for each included study. - high risk, +: low risk, ?: unclear risk. 


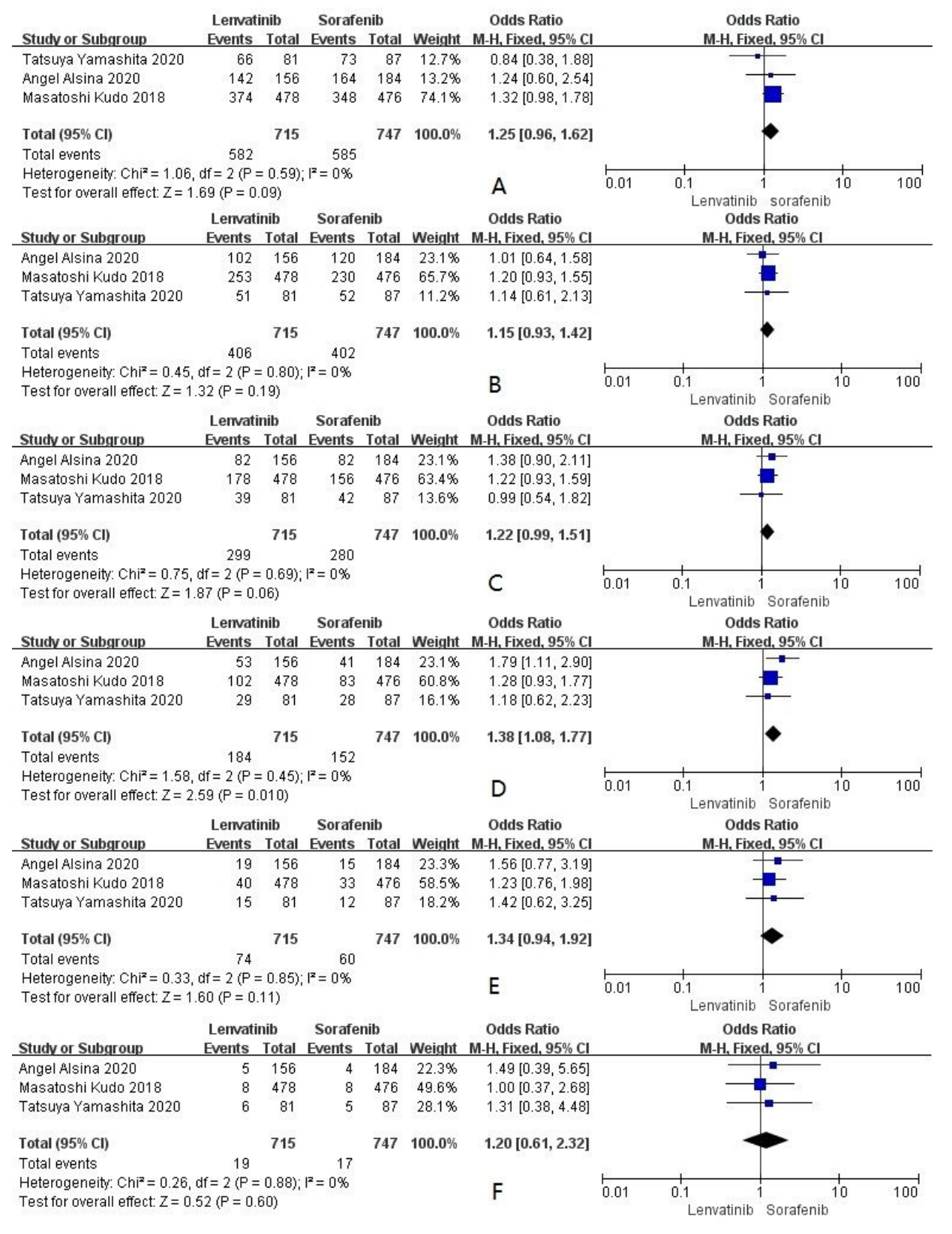

\section{Figure 3}

(A-F): Forest plot for OS of $6,12,6,12,18,30$ and 36 months. 


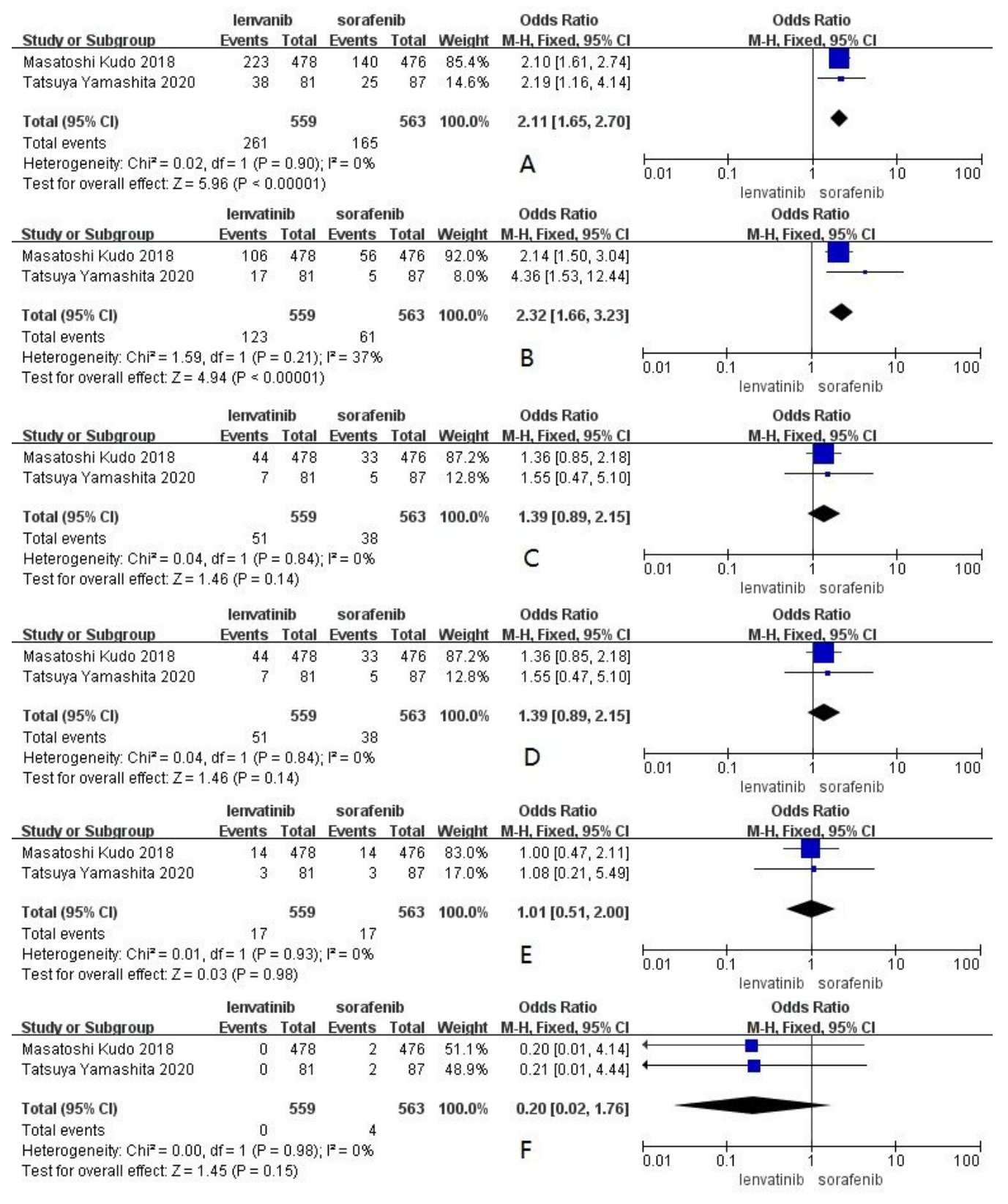

\section{Figure 4}

(A-F): Forest plot for PFS of $6,12,6,12,18,30$ and 36 months.

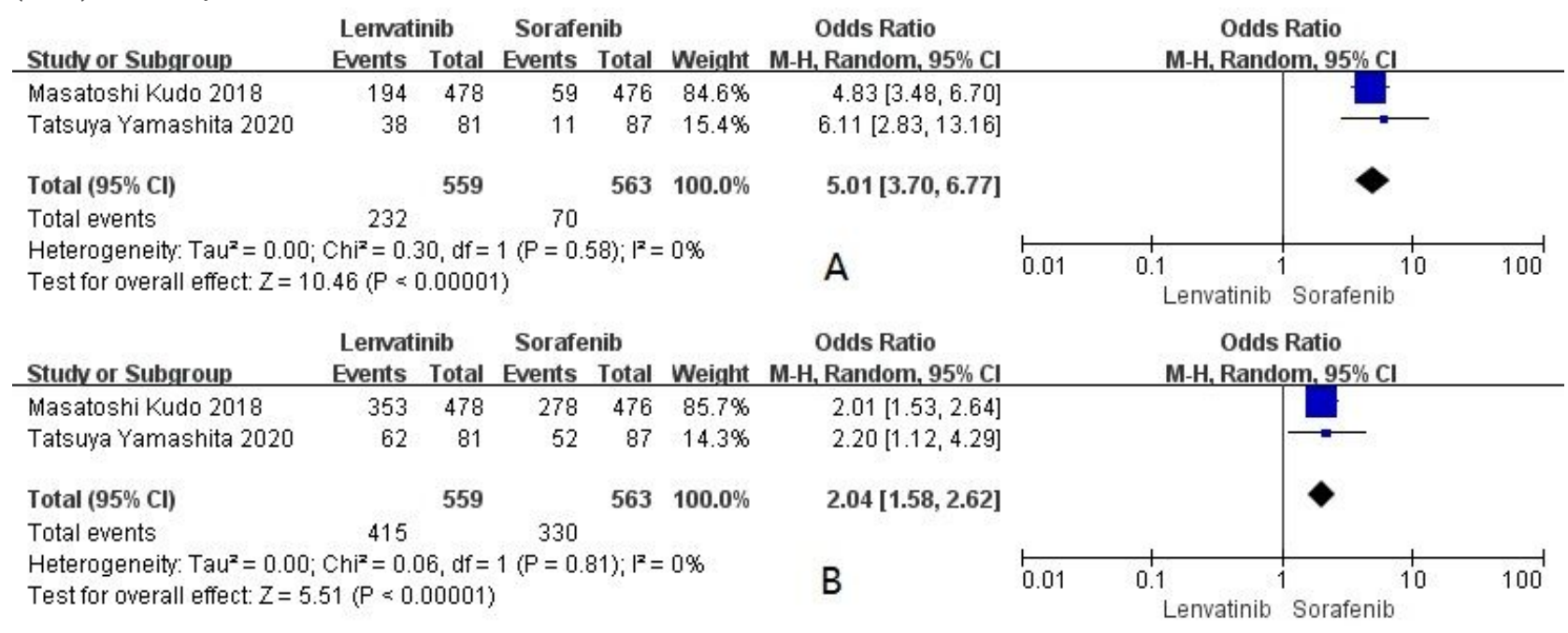


Figure 5

$(A, B)$ : Forest plot for ORR and DCR.

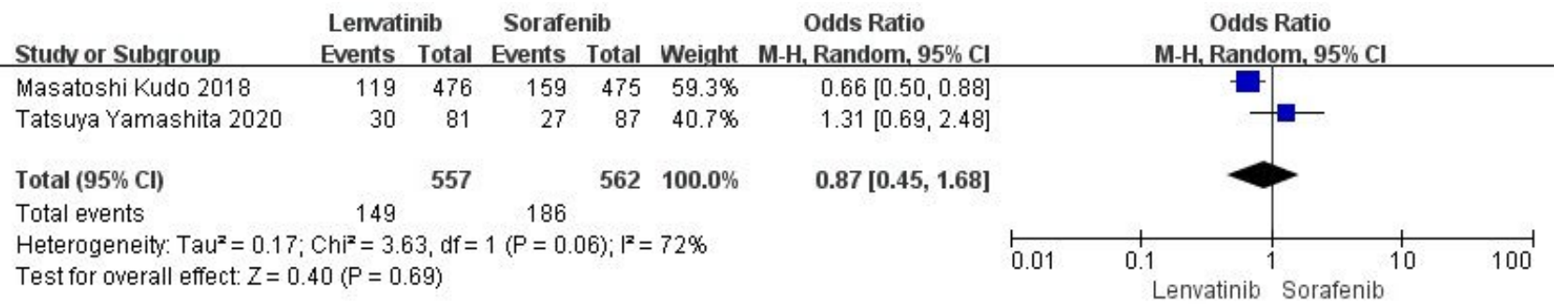

\section{Figure 6}

Forest plot for AEs.

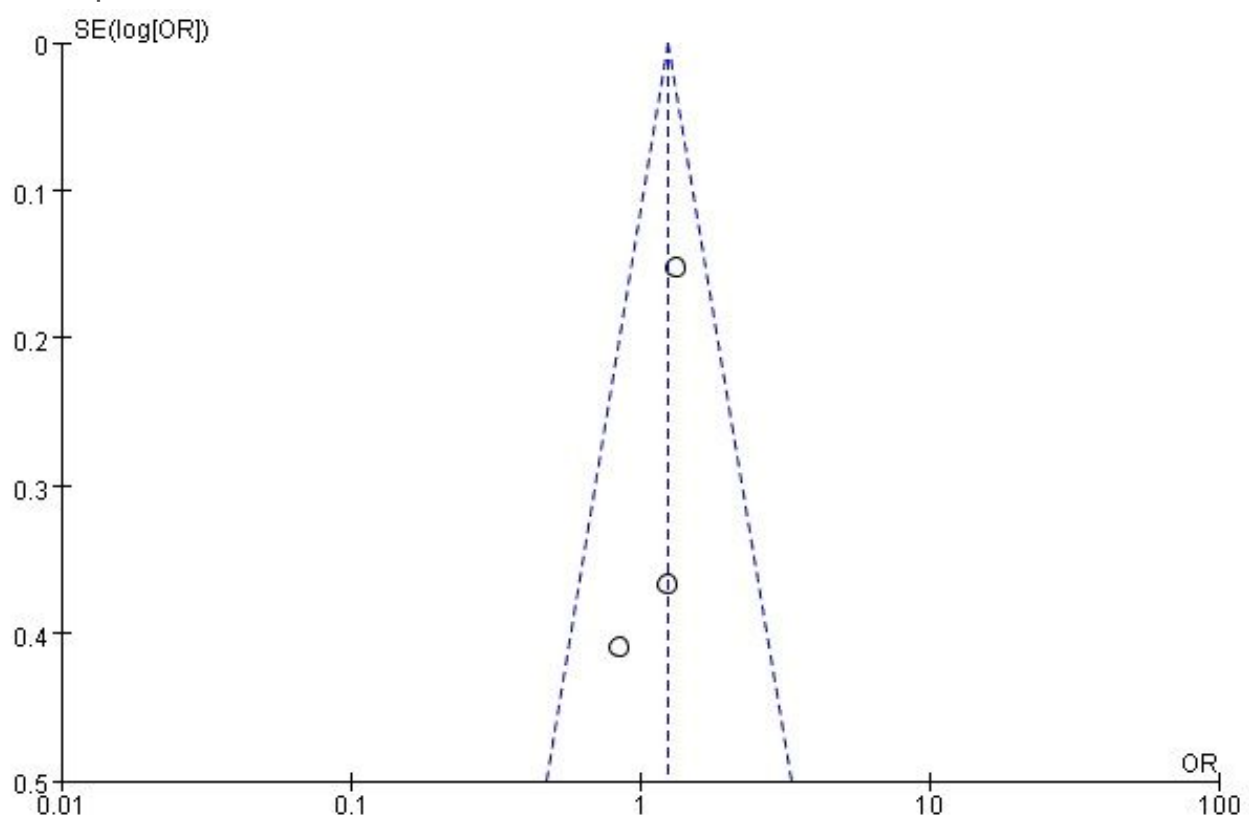

Figure 7

Funnel plot of publication bias 